\title{
Serum iron levels as a new biomarker in chemotherapy with leucovorin and fluorouracil plus oxaliplatin or leucovorin and fluorouracil plus irinotecan, with or without molecularly-targeted drugs
}

\author{
TAKUMI OCHIAI ${ }^{1}$, KAZUHIKO NISHIMURA $^{1}$, TOMOO WATANABE $^{1}$, MASAYUKI KITAJIMA $^{1}$, \\ AKINORI NAKATANI ${ }^{1}$, TAKASHI INOU ${ }^{1}$, HIDEKI SHIBATA ${ }^{1}$, TSUYOSHI SATO ${ }^{1}$, KENJI KISHINE ${ }^{1}$, \\ SHOUGO SEO $^{1}$, SATOSHI OKUBO ${ }^{1}$, SHUNJI FUTAGAWA ${ }^{1}$, SATOMI MASHIKO $^{2}$ and ISAO NAGAOKA ${ }^{3}$ \\ Departments of ${ }^{1}$ Surgery and ${ }^{2}$ Pharmacy, Tobu Chiiki Hospital, Tokyo Metropolitan Health and Medical Treatment \\ Corporation, Tokyo 125-8512; ${ }^{3}$ Department of Host Defense and Biochemical Research, Juntendo University \\ School of Medicine, Tokyo 113-8421, Japan
}

Received December 28, 2012; Accepted May 15, 2013

DOI: $10.3892 / \mathrm{mco} .2013 .136$

\begin{abstract}
Serum iron levels have been reported to increase following the administration of various anticancer drugs. An increase in serum iron levels during therapy with leucovorin and fluorouracil plus oxaliplatin (FOLFOX) or leucovorin and fluorouracil plus irinotecan (FOLFIRI) was also observed. The aim of this study was to investigate the correlation between serum iron levels and prognosis in advanced colorectal cancer (CRC) patients treated with FOLFOX/FOLFIRI \pm molecularly-targeted drugs. Serum iron levels were measured prior to and at $48 \mathrm{~h}$ after treatment with FOLFOX/FOLFIRI \pm molecularly-targeted drugs in 72 advanced CRC patients, all of whom succumbed to the disease between December, 2005 and February, 2012. No patients received radiotherapy. Taking the median rate of increase in serum iron levels as the cut-off value in each therapy, the patients were divided into cohort I (increase rate greater than the cut-off value in at least one therapy) or cohort II (increase rate less than the cut-off value in all therapies). The $\chi^{2}$ test and the t-test were used to compare patient characteristics between the two cohorts. Prognosis was evaluated between the two cohorts using the Kaplan-Meier method, the log-rank test and the Cox proportional hazards regression analysis. No significant bias in patient char-
\end{abstract}

Correspondence to: Dr Takumi Ochiai, Department of Surgery, Tobu Chiiki Hospital, Tokyo Metropolitan Health and Medical Treatment Corporation, 5-14-1 Kameari, Katsushika, Tokyo 125-8512, Japan

E-mail: takumi-o@ma.kitanet.ne.jp

Key words: serum iron levels, biomarker, chemotherapy, leucovorin and fluorouracil plus oxaliplatin, leucovorin and fluorouracil plus irinotecan acteristics (including the frequency of chemotherapy or number of patients treated with molecularly-targeted drugs) was observed between the two cohorts. Serum iron levels were transiently elevated following treatment $(\mathrm{P}<0.001)$, returning to baseline within 2 weeks. Median survival time (MST) in cohort I $(n=44)$ and cohort II $(n=28)$ was 430 and 377 days, respectively. The MST was significantly higher in cohort I $(\mathrm{P}=0.0382)$. The multivariate analysis identified a small increase in serum iron levels as an independent risk factor for overall survival (OS). These results suggest that serum iron levels may be used as a new predictive factor in FOLFOX/FOLFIRI \pm molecularly-targeted drug therapy. Serum iron levels may therefore prove to be a useful and convenient biomarker for OS in CRC patients.

\section{Introduction}

The prediction of the host response to an administered therapy by means of a serum biomarker may offer a useful and convenient prognostic or predictive factor in the planning of cancer treatment. Follézou and Bizon (1) reported an increase in serum iron levels following administration of various anticancer drugs, including 5-FU, actinomycin D, adriamycin and cyclophosphamide. Recently, we also reported a significant increase in serum iron levels during therapy with leucovorin and fluorouracil plus oxaliplatin (FOLFOX) or leucovorin and fluorouracil plus irinotecan (FOLFIRI). Moreover, the levels of aspartate aminotransferase, alanine aminotransferase and hemoglobin were unaffected and the levels of transferrin and ferritin were only minimally altered during chemotherapy, while a molecularly-targeted drug exerted no effect on serum iron levels (2).

The aim of this study was to investigate the correlation between serum iron levels and prognosis in advanced colorectal cancer (CRC) patients treated with FOLFOX/FOLFIRI \pm molecularly-targeted drugs, in order to establish their potential as a new biomarker. 


\section{Patients and methods}

Patients. Seventy-two patients with unresectable advanced or metastatic CRC were enrolled in this study. Treatments based on the Japanese Society for Cancer of the Colon and Rectum guidelines were administered to all the patients at our institution (3). Patients were treated with FOLFOX or FOLFIRI therapy alone or in combination with molecularly-targeted drugs (bevacizumab/cetuximab/panitumumab). All patients succumbed to their disease between December, 2005 and February, 2012. No patients received radiotherapy. Informed consent for the measurement of serum iron levels was obtained from the patients. Approval for this study was obtained from the Tobu Chiiki Hospital Institutional Review Board (no. 12.09.10. no. 2).

Serum iron levels. Serum iron levels were measured as part of routine blood analysis at our hospital laboratory prior to and $48 \mathrm{~h}$ after chemotherapy, to determine whether an adverse reaction had occurred. The normal range of serum iron levels was established as $60-210 \mu \mathrm{g} / \mathrm{dl}$ for men and 50-170 $\mu \mathrm{g} / \mathrm{dl}$ for women. Changes in serum iron levels during chemotherapy were assessed. Taking the median rate of increase in serum iron levels as the cut-off value in each therapy, the patients were divided into two cohorts: cohort I (increase rate greater than the cut-off value in at least one therapy) or cohort II (increase rate less than the cut-off value in all therapies). Prognosis was prospectively evaluated and compared between the two cohorts.

Statistical analysis. Patient characteristics were compared between the two cohorts using the $\chi^{2}$ test (gender, number of patients treated with molecularly-targeted drugs, Dukes' stage, histological type, primary tumor site and recurrence type) and the t-test (age and frequency of chemotherapy). The median survival time (MST) by cut-off value of serum iron levels was calculated by the Kaplan-Meier method. The overall survival (OS) curves of the two cohorts as determined by the cut-off value were compared by the log-rank test. The Cox proportional hazards regression analysis was used in the univariate and multivariate analyses of prognostic factors for OS. $\mathrm{P}<0.05$ was considered to indicate a statistically significant difference. Data were expressed as the means \pm SD and were analyzed using SPSS for Windows version 15 (SPSS Inc., Chicago, IL, USA).

\section{Results}

Patient characteristics and serum iron levels. The patient characteristics are shown in Table I. The typical pattern of change in the serum iron levels prior to and following each chemotherapy regimen is shown in Fig. 1. The serum iron levels were transiently elevated following treatment, returning to baseline within 2 weeks. The serum iron level was $68.16 \pm 32.46 \mu \mathrm{g} / \mathrm{dl}$ prior to treatment, increasing significantly to $185.87 \pm 80.11 \mu \mathrm{g} / \mathrm{dl}$ following treatment (1,454 blood samples, $\mathrm{P}<0.001$, Fig. 2$)$. The median increase rate in the serum iron levels (cut-off value) is shown in Table II. No significant bias in patient characteristics was observed between cohorts I $(n=44)$ and II $(n=28)$ (Table III).

Prognosis. The MST in cohorts $\mathrm{I}(\mathrm{n}=44)$ and II $(\mathrm{n}=28)$ was 430 and 377 days, respectively. The MST was significantly higher in
Table I. Patient characteristics.

\begin{tabular}{lc}
\hline Variables & Value \\
\hline No. of patients & 72 \\
Age in years [mean, (range)] & $70.1(45-84)$ \\
Gender (male/female) & $41 / 31$ \\
Histological type & \\
Adenocarcinoma & \\
Well-differentiated & 8 \\
Moderately-differentiated & 50 \\
Poorly-differentiated & 4 \\
Mucinous carcinoma & 8 \\
Unknown & 2 \\
Primary cancer site & \\
Colon/rectum & $54 / 18$ \\
Dukes' stage (A/B/C/D) & $1 / 6 / 35 / 30$ \\
Recurrence type & \\
Lymph node & 4 \\
Liver & 33 \\
Local recurrence & 3 \\
Bone & 2 \\
Mediastinum & 1 \\
Lung & 12 \\
Unresectable & 7 \\
Peritoneum & $99 / 43$ \\
Ovary & \\
Molecularly-targeted drug (+/-) & \\
Frequency of chemotherapy (range) & \\
& \\
&
\end{tabular}

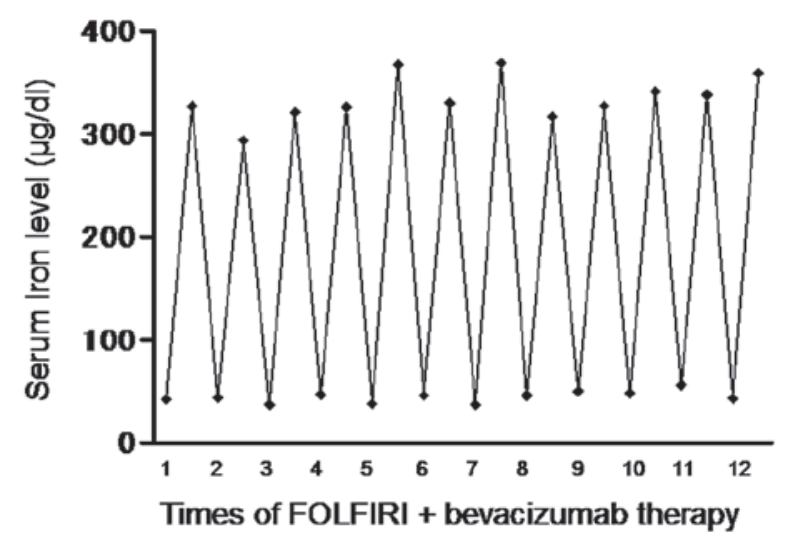

Figure 1. Typical pattern change of serum iron levels prior to and following therapy with leucovorin and fluorouracil plus irinotecan (FOLFIRI) + bevacizumab.

cohort I ( $\mathrm{P}=0.0382)$ (Fig. 3). The results of univariate analysis are shown in Table IV. A significant difference was observed in the serum iron levels. Multivariate analysis identified a small increase in the serum iron levels as an independent risk factor for OS (Table V). 
Table II. Median increase rate in serum iron levels (cut-off values).

\begin{tabular}{lccc}
\hline Parameters & FOLFOX4 $(\mathrm{n}=96)$ & mFOLFOX6 $(\mathrm{n}=4)$ & FOLFIRI $(\mathrm{n}=69)$ \\
\hline Alone & $214.2 \%(\mathrm{n}=65)$ & $577.3 \%(\mathrm{n}=2)$ & $344.3 \%(\mathrm{n}=41)$ \\
Molecularly-targeted drug & $190.2 \%(\mathrm{n}=31)$ & $501.6 \%(\mathrm{n}=2)$ & $395.3 \%(\mathrm{n}=28)$ \\
\hline
\end{tabular}

FOLFOX, leucovorin and fluorouracil plus oxaliplatin; FOLFOX4, day 1: oxaliplatin $85 \mathrm{mg} / \mathrm{m}^{2}$, L-leucovorin $100 \mathrm{mg} / \mathrm{m}^{2}$ (L-isomer form), fluorouracil bolus $400 \mathrm{mg} / \mathrm{m}^{2}$, fluorouracil infusion $600 \mathrm{mg} / \mathrm{m}^{2}$ for $22 \mathrm{~h}$, day 2 : L-leucovorin $100 \mathrm{mg} / \mathrm{m}^{2}$, fluorouracil bolus $400 \mathrm{mg} / \mathrm{m}^{2}$, fluorouracil infusion $600 \mathrm{mg} / \mathrm{m}^{2}$ for $22 \mathrm{~h}$; mFOLFOX6, oxaliplatin $85 \mathrm{mg} / \mathrm{m}^{2}$, L-leucovorin $200 \mathrm{mg} / \mathrm{m}^{2}$, fluorouracil bolus $400 \mathrm{mg} / \mathrm{m}^{2}$, fluorouracil infusion 2,400 mg/m² over $46 \mathrm{~h}$; FOLFIRI, leucovorin and fluorouracil plus irinotecan; $\mathrm{n}$, number of patients.

Table III. Patient characteristics.

\begin{tabular}{|c|c|c|c|}
\hline Variables & Cohort I & Cohort II & P-value \\
\hline No. of patients & 44 & 28 & \\
\hline Age in years [mean, (range)] & $71.8(53-84)$ & $67.5(45-81)$ & 0.062 \\
\hline Gender (male/female) & $27 / 17$ & $14 / 14$ & 0.464 \\
\hline Histological type & & & 0.181 \\
\hline \multicolumn{4}{|l|}{ Adenocarcinoma } \\
\hline Well-differentiated & 4 & 4 & \\
\hline Moderately-differentiated & 30 & 20 & \\
\hline Poorly-differentiated & 3 & 1 & \\
\hline Mucinous carcinoma & 7 & 1 & \\
\hline Unknown & 0 & 2 & \\
\hline \multicolumn{4}{|l|}{ Primary cancer site } \\
\hline Colon/rectum & $34 / 10$ & $20 / 8$ & 0.463 \\
\hline Dukes' stage (A/B/C/D) & $1 / 3 / 24 / 16$ & $0 / 3 / 11 / 14$ & 0.470 \\
\hline Recurrence type & & & 0.096 \\
\hline Lymph node & 3 & 1 & \\
\hline Liver & 19 & 14 & \\
\hline Local recurrence & 3 & 0 & \\
\hline Bone & 0 & 2 & \\
\hline Mediastinum & 0 & 1 & \\
\hline Lung & 10 & 2 & \\
\hline Unresectable & 2 & 5 & \\
\hline Peritoneum & 6 & 3 & \\
\hline Ovary & 1 & 0 & \\
\hline Molecularly-targeted drug (+/-) & $21 / 23$ & $8 / 20$ & 0.141 \\
\hline Frequency of chemotherapy (range) & $23.6(1-73)$ & $18.3(1-41)$ & 0.113 \\
\hline
\end{tabular}

\section{Discussion}

$\mathrm{CRC}$ is the third most common type of cancer worldwide and the fourth most common cause of cancer-related mortality (4). The OS rate in advanced CRC patients has increased over the past decade as a result of advances in chemotherapy. An increase in serum iron levels with the administration of various anticancer drugs was first reported several decades ago. We recently reported a significant increase in serum iron levels during FOLFOX or FOLFIRI therapy (2). In the present study, serum iron levels were investigated as a potential new biomarker of prognosis in chemotherapy.

Biomarkers play an important role in cancer diagnosis, prognosis, treatment and monitoring. Several biomarkers have been investigated with the development of new molecular biological techniques and advances in cancer biology. Preoperative increases in the serum levels of carcinoembryonic antigen, C-reactive protein (CRP), pro-inflammatory cytokine interleukin-6 (IL-6) and other markers have been reported to provide prognostic information (5-16). Prognostic 
Table IV. Univariate analysis of overall survival.

\begin{tabular}{|c|c|c|c|c|}
\hline Variables & No. of patients & Hazard ratio & $95 \%$ CI & P-value \\
\hline Age (years) & & 0.964 & $0.574-1.620$ & 0.891 \\
\hline$<75$ & 51 & & & \\
\hline $75 \leq$ & 21 & & & \\
\hline Gender & & 0.622 & $0.378-1.022$ & 0.061 \\
\hline Male & 42 & & & \\
\hline Female & 30 & & & \\
\hline Histological type & & 0.657 & $0.364-1.188$ & 0.164 \\
\hline Differentiated & 58 & & & \\
\hline Undifferentiated/unknown & 14 & & & \\
\hline Primary site & & 0.720 & $0.417-1.242$ & 0.238 \\
\hline Colon & 54 & & & \\
\hline Rectum & 18 & & & \\
\hline Dukes' stage & & 1.236 & $0.764-1.999$ & 0.388 \\
\hline $\mathrm{A} / \mathrm{B} / \mathrm{C}$ & 42 & & & \\
\hline $\mathrm{D}$ & 30 & & & \\
\hline Recurrence type & & 1.767 & 0.894-3.494 & 0.102 \\
\hline Local recurrence/Unresectable & 10 & & & \\
\hline Metastasis & 62 & & & \\
\hline Serum iron level & & 1.686 & $1.023-2.779$ & 0.040 \\
\hline Cohort I & 44 & & & \\
\hline Cohort II & 28 & & & \\
\hline
\end{tabular}

CI, confidence interval.

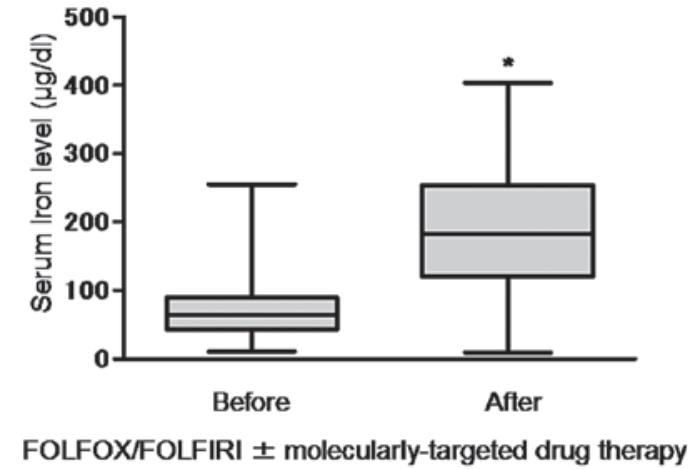

Figure 2. Change in serum iron levels prior to and following therapy with leucovorin and fluorouracil plus oxaliplatin (FOLFOX)/leucovorin and fluorouracil plus irinotecan (FOLFIRI) \pm molecularly-targeted drug. Serum iron levels were measured in 1,454 blood samples. Data are presented as the means $\pm \mathrm{SD}$; values prior to and following chemotherapy were compared ${ }^{*} \mathrm{P}<0.001$.

factors for human CRC have been the focus of extensive investigation (17-19). Serum biomarkers have attracted attention as they offer a minimally invasive and convenient tool for determining prognosis. Serum iron levels are determined during the course of routine blood analysis. Therefore, they are a potential easy-to-use biomarker for chemotherapy in advanced CRC patients.

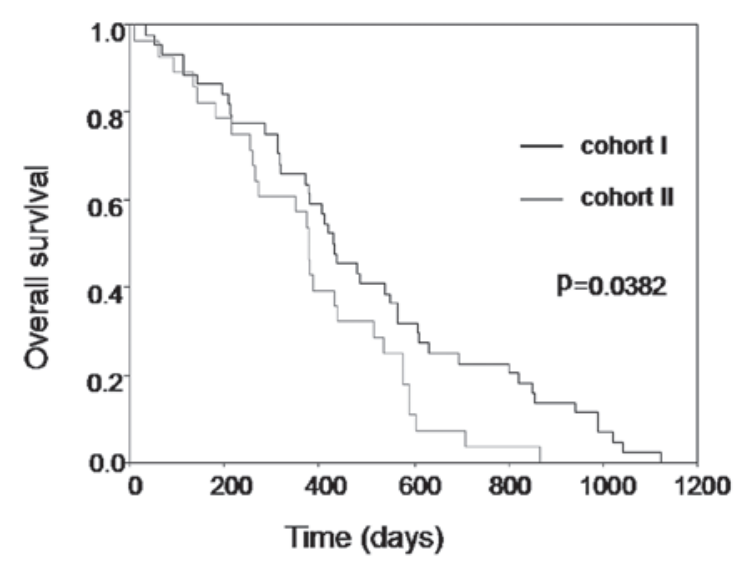

Figure 3. Overall survival rates in cohorts I (black line) and II (gray line).

Iron is essential to all human cells, playing an important role in numerous biological processes, such as electron and oxygen transport and DNA synthesis $(20,21)$. However, excess iron poses a threat to cells and tissues due to its ability to catalyze the generation of reactive radicals (22). Therefore, serum iron levels are strictly regulated in the human body (23), mainly by the peptide hepcidin, which is produced in the liver (24-26). Hepcidin is a key regulator of the metabolism 
Table V. Multivariate analysis of overall survival.

\begin{tabular}{|c|c|c|c|c|}
\hline Variables & No. of patients & Hazard ratio & $95 \% \mathrm{CI}$ & P-value \\
\hline Age (years) & & 1.216 & $0.664-2.229$ & 0.526 \\
\hline$<75$ & 51 & & & \\
\hline $75 \leq$ & 21 & & & \\
\hline Gender & & 0.561 & $0.297-1.061$ & 0.075 \\
\hline Male & 42 & & & \\
\hline Female & 30 & & & \\
\hline Histological type & & 0.589 & $0.285-1.219$ & 0.154 \\
\hline Differentiated & 58 & & & \\
\hline Undifferentiated/unknown & 14 & & & \\
\hline Primary site & & 0.731 & $0.389-1.375$ & 0.331 \\
\hline Colon & 54 & & & \\
\hline Rectum & 18 & & & \\
\hline Dukes' stage & & 1.333 & $0.789-2.250$ & 0.283 \\
\hline $\mathrm{A} / \mathrm{B} / \mathrm{C}$ & 42 & & & \\
\hline $\mathrm{D}$ & 30 & & & \\
\hline Recurrence type & & 2.096 & $0.960-4.575$ & 0.063 \\
\hline Local recurrence/unresectable & 10 & & & \\
\hline Metastasis & 62 & & & \\
\hline Serum iron level & & 1.961 & $1.143-3.365$ & 0.015 \\
\hline Cohort I & 44 & & & \\
\hline Cohort II & 28 & & & \\
\hline
\end{tabular}

CI, confidence interval.

of iron, controlling absorption and recycling $(27,28)$. Hepcidin decreases intestinal iron absorption and increases its retention in reticuloendothelial cells (26). The target of hepcidin action is the iron exporter ferroportin, which is mainly present in the basolateral membranes of enterocytes and the cell membranes of macrophages and hepatocytes (29). Hepcidin is increased by iron loading and IL- 6 and decreased by anemia or hypoxia (27,30-33). The majority of the iron required by the bone marrow for erythropoiesis is provided by recycling iron from senescent red blood cells via macrophages.

In this study, serum iron levels were transiently elevated following chemotherapy, returning to baseline within 2 weeks. A number of factors may have contributed to this phenomenon. Erythropoiesis, which consumes the largest amount of iron in the body, exerting a profound effect on its distribution and metabolism, is suppressed by chemotherapy. The subsequent reduction in iron consumption for hemoglobin synthesis may have caused this transient increase in serum iron levels. Vokurka et al (34) observed an increase in the expression of hepcidin associated with the irradiation-induced suppression of erythropoiesis in mice. Continuous iron absorption in the gut and its release from macrophages is highly undesirable in situations where erythropoiesis is suppressed. Moreover, the increase in the expression of hepcidin was observed even in the presence of severe anemia due to inhibition of hematopoiesis by irradiation. Hemolysis and anemia decrease hepcidin expression only when erythropoiesis is functional. However, if erythropoiesis is arrested, even severe anemia does not lead to a decrease in hepcidin expression, which is significantly increased. Hepcidin expression during chemotherapy was not measured in the present study. However, if such an increase in the expression of hepcidin was triggered by chemotherapy, the underlying mechanism may be similar to that induced by irradiation.

There were several limitations to this study. First, the patient sample was limited. A larger patient sample may improve data quality. Second, although serum iron levels appear to be a biomarker for OS, the correlation between the increase in serum iron levels and prognosis has not been fully elucidated, nor has that between increases in CRP or IL-6 and prognosis. In addition to cancer cells, chemotherapy suppresses erythropoiesis. If an increase in serum iron levels is the result of suppression of erythropoiesis, this may also indicate suppression of cancer cell proliferation. Third, neither hepcidin as a key regulator of iron metabolism nor IL-6 as a main inducer of hepcidin expression were investigated in the present study. A study on a larger patient population is currently being planned to investigate the association of systemic iron metabolism with the clinical outcome of chemotherapy.

In conclusion, no significant difference was observed in the frequency of chemotherapy or the number of patients treated with molecularly-targeted drugs between the two cohorts. 
Cohort I exhibited a statistically significant improvement in prognosis. Furthermore, the multivariate analysis revealed that the change in serum iron levels was an independent predictive variable. These results suggest that serum iron levels may be a useful and convenient biomarker for OS in CRC patients.

\section{Acknowledgements}

The authors would like to thank Associate Professor Jeremy Williams, Tokyo Dental College, for his assistance with the English translation of this manuscript.

\section{References}

1. Follézou JY and Bizon M: Cancer chemotherapy induces a transient increase of serum-iron level. Neoplasma 33: 225-231, 1986.

2. Mashiko S, Nagaoka I, Kitajima M, et al: Evaluation of serum iron levels during FOLFOX4 and FOLFIRI therapies. Exp Ther Med 1: 507-511, 2010.

3. Watanabe T, Itabashi M, Shimada Y, et al: Japanese Society for Cancer of the Colon and Rectum (JSCCR) guidelines 2010 for the treatment of colorectal cancer. Int J Clin Oncol 17: 1-29, 2012.

4. Weitz J, Koch M, Debus J, et al: Colorectal cancer. Lancet 365: $153-165,2005$

5. Proctor MJ, Talwar D, Balmar SM, et al: The relationship between the presence and site of cancer, an inflammation-based prognostic score and biochemical parameters. Initial results of the Glasgow Inflammation Outcome Study. Br J Cancer 103: 870-876, 2010

6. McMillan DC: An inflammation-based prognostic score and its role in the nutrition-based management of patients with cancer. Proc Nutr Soc 67: 257-262, 2008.

7. McMillan DC: Systemic inflammation, nutritional status and survival in patients with cancer. Curr Opin Clin Nutr Metab Care 12: 223-226, 2009.

8. Roxburgh CS and McMillan DC: Role of systemic inflammatory response in predicting survival in patients with primary operable cancer. Future Oncol 6: 149-163, 2010.

9. Balkwill $\mathrm{F}$ and Mantovani A: Inflammation and cancer: back to Virchow? Lancet 357: 539-545, 2001.

10. Coussens LM and Werb Z: Inflammation and cancer. Nature 420: 860-867, 2002.

11. Mantovani A, Romero P, Palucka AK and Marincola FM: Tumour immunity: effector response to tumour and role of the microenvironment. Lancet 371: 771-783, 2008.

12. McDonald B, Spicer J, Giannais B, et al: Systemic inflammation increases cancer cell adhesion to hepatic sinusoids by neutrophil mediated mechanisms. Int J Cancer 125: 1298-1305, 2009.

13. Colotta F, Allavena P, Sica A, et al: Cancer-related inflammation, the seventh hallmark of cancer: links to genetic instability. Carcinogenesis 30: 1073-1081, 2009.

14. Marsik C, Kazemi-Shirazi L, Schickbauer T, et al: C-reactive protein and all-cause mortality in a large hospital-based cohort Clin Chem 54: 343-349, 2008.

15. Goldwasser P and Feldman J: Association of serum albumin and mortality risk. J Clin Epidemiol 50: 693-703, 1997.
16. Deans $\mathrm{C}$ and Wigmore SJ: Systemic inflammation, cachexia and prognosis in patients with cancer. Curr Opin Clin Nutr Metab Care 8: 265-269, 2005.

17. Tsushima H, Ito N, Tamura S, et al: Circulating transforming growth factor beta 1 as a predictor of liver metastasis after resection in colorectal cancer. Clin Cancer Res 7: 1258-1262, 2001.

18. Toiyama Y, Fujikawa H, Kawamura M, et al: Evaluation of CXCL10 as a novel serum marker for predicting liver metastasis and prognosis in colorectal cancer. Int J Oncol 40: 560-566, 2012.

19. Sharma R, Zucknick M, London R, et al: Systemic inflammatory response predicts prognosis in patients with advanced-stage colorectal cancer. Clin Colorectal Cancer 7: 331-337, 2008.

20. Ponka P: Cellular iron metabolism. Kidney Int Suppl 69: S2-S11, 1999.

21. Aisen P, Enns C and Wessling-Resnick M: Chemistry and biology of eukaryotic iron metabolism. Int $\mathrm{J}$ Biochem Cell Biol 33: 940-959, 2001.

22. Papanikolaou G and Pantopoulos K: Iron metabolism and toxicity. Toxicol Appl Pharmacol 202: 199-211, 2005.

23. Knutson $M$ and Wessling-Resnick M: Iron metabolism in the reticuloendothelial system. Crit Rev Biochem Mol Biol 38: 61-88, 2003.

24. Krause A, Neitz S, Magert HJ, et al: LEAP-1, a novel highly disulfide-bonded human peptide, exhibits antimicrobial activity. FEBS Lett 480: 147-150, 2000.

25. Park CH, Valore EV, Waring AJ, et al: Hepcidin, a urinary antimicrobial peptide synthesized in the liver. J Biol Chem 276: 7806-7810, 2001.

26. Kemna EH, Tjalsma H, Willems HL and Swinkels DW: Hepcidin: from discovery to differential diagnosis. Haematologica 93: 90-97, 2008.

27. Pigeon C, Ilyin G, Courselaud B, et al: A new mouse liver-specific gene, encoding a protein homologous to human antimicrobial peptide hepcidin, is overexpressed during iron overload. J Biol Chem 276: 7811-7819, 2001.

28. Nicolas G, Bennoun M, Devaux I, et al: Lack of hepcidin gene expression and severe tissue iron overload in upstream stimulatory factor 2 (USF2) knockout mice. Proc Natl Acad Sci USA 98: 8780-8785, 2001.

29. Nemeth E, Tuttle MS, Powelson J, et al: Hepcidin regulates cellular iron efflux by binding to ferroportin and inducing its internalization. Science 306: 2090-2093, 2004

30. Nicolas G, Chauvet C, Viatte L, et al: The gene encoding the iron regulatory peptide hepcidin is regulated by anemia, hypoxia, and inflammation. J Clin Invest 110: 1037-1044, 2002.

31. Nemeth E, Valore EV, Territo M, et al: Hepcidin, a putative mediator of anemia of inflammation, is a type II acute-phase protein. Blood 101: 2461-2463, 2003.

32. Nemeth E, Rivera S, Gabayan V, et al: IL-6 mediates hypoferremia of inflammation by inducing the synthesis of the iron regulatory hormone hepcidin. J Clin Invest 113: 1271-1276, 2004.

33. Pietrangelo A, Dierssen U, Valli L, et al: STAT3 is required for IL-6-gp130-dependent activation of hepcidin in vivo. Gastroenterology 132: 294-300, 2007.

34. Vokurka M, Krijt J, Sulc K and Necas E: Hepcidin mRNA levels in mouse liver respond to inhibition of erythropoiesis. Physiol Res 55: 667-674, 2006. 